\title{
The Impact Of Team Climate ON FaIlure AND SUCCESS OF SCRUM ADOPTION
}

\author{
Mona Najafi Sarpiri ${ }^{1}$ and Taghi Javdani Gandomani ${ }^{2 *}$ \\ ${ }^{1}$ Department of Computer Engineering, Dolat Abad Branch, Islamic Azad University, \\ Dolat Abad, Isfahan, Iran \\ ${ }^{2 *}$ Department of Computer Engineering, Boroujen Branch, Islamic Azad University, \\ Boroujen, Iran
}

\begin{abstract}
Software companies are widely using Agile methods in recent years. Scrum is the most popular Agile method which focuses on project management by defining the required roles, responsibilities, and activities. Despite of its simplicity, many reports address the challenges that threat the software teams when adapting to Scrum. Most of these reports highlight the details of the challenges which most of them roots back to the team climate. On the other hand, it seems that Scrum facilitators originate from the team climate, too. This study aimed to show the impact of software team climate on both failure and success of Scrum adoption. The results show that team climate has positive and negative impact on Scrum adoption process.
\end{abstract}

\section{KEYWORDS}

Agile Methods, Scrum, Scrum Adoption, Team Climate, Scrum Failure, Scrum Challenges

\section{INTRODUCTION}

Scrum is known as a software development framework that its primarily focus is on project management. This framework is widely used is many software teams and companies recently [1]. Scrum promotes iterative and incremental software development by defining short iterations known as Sprint. Tough, its simple structure, Scrum adoption is not easy, as addressed in the several studies.

Scrum dramatically relies on the involved people including technical and business parties as well as senior managers. This is mainly because of the people-oriented nature of this framework that roots back to Agile principles defined in the Agile manifesto [2]. So, people plays a critical role during application of Scrum in software projects.

Several studies have been conducted to describe various aspects of Scrum adoption in software companies [3-5]. Most of them reported the potential challenges, obstacles, and barriers teams are facing throughout the adoption process. Most of the challenges are associated with human related aspects of software development practices [3,5]. It seems that software teams need to be aware of the challenges and have to ready to cope with them. The main aim of this paper is to provide human related factors which lead to success of the Scrum adoption. 
The rest this paper is organized as follows: Section 2 explains the main structure of the Scrum framework by emphasis on its human related practices. Section 3 provides the main human related challenges of Scrum adoption, followed by Section 4 which shows how team climate results in success of Scrum adoption. Finally, Section 5 provides a brief conclusion.

\section{SCRUM FRAMEWORK}

Scrum has been proposed to facilitate the project management in software process [6]. Scrum provides three phases, namely Pre-game, Game, Post-game [7]. Pre-game phase deals with overall planning and architecture design. Game phase, known as development, is the heart of Scrum which product development is done in an iterative and incremental manner. Finally, Postgame provides the required system-wide testing and iterative release [7].

Scrum required recruiting qualified experts in its defined role; Scrum Master, Product Owner, and development team members [8]. Scrum Master is a servant leader who promote Scrum and remove the obstacles and challenges threaten the development team. Product Owner is responsible to clearly define customer requirements (called User Stories) and put them in a Scrum-defined artifact known as Product Backlog. Product Owner is also responsible to prioritize the Product Backlog based on their values as expected by customer [8]. Development team members collaborate to estimate the required effort for developing of each user stories in advance. This framework suggests to develop software products by conducting several sprints each takes two to four weeks. Development team pick a subset of User Stories collected in the Product Backlog and put them in a smaller list, called Sprint Backlog. Then, the team tries to development them throughout one Sprint. Fig. 1 shows Scrum framework and its main steps.

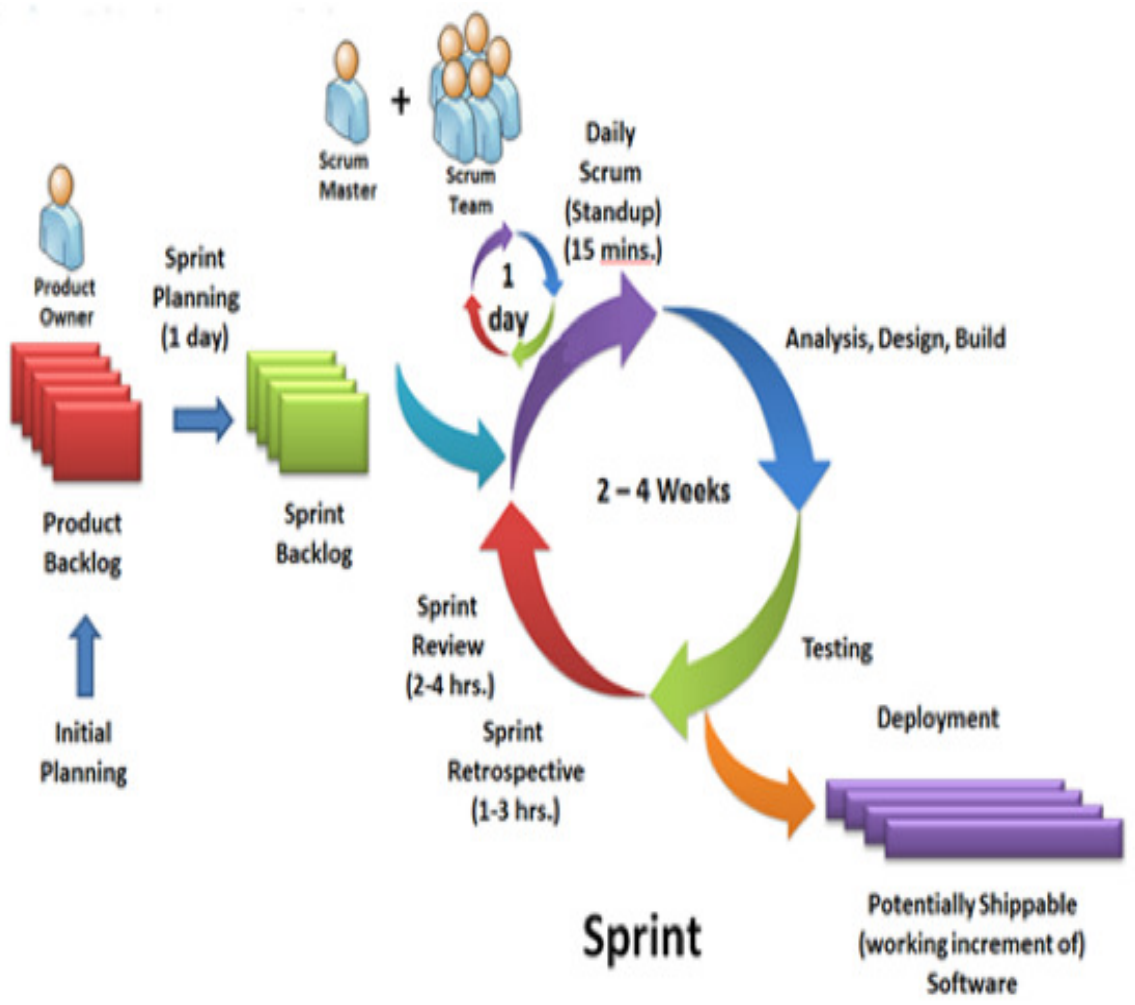

Figure 1. Scrum framework 
International Journal of Software Engineering \& Applications (IJSEA), Vol.8, No.3, May 2017

People communications and collaborations are strongly affects the quality of Scrum. This is mainly because Scrum puts its emphasis on informal relationships rather that formal communications [9]. Thus, knowledge management is based on implicit knowledge.

Human resources are the core of Scrum where it focuses on hiring experienced and responsible experts. All the involved people including customer representative, managers, and team members need to respect the Agile values promised by Scrum. Scrum teams are self-organizing teams that do not need to be managed or controlled by managers [6]. Also, development team members are cross-functional experts who have enough experience in all technical roles. Also, they need enough social skills to facilitate their communications and collaborations with other team members.

\section{Challenges of SCRum Adoption}

Despite of various benefits and advantages of Scrum, its application is not easy in real environments. In fact, many studies reported the challenges they faced while adapting to Scrum. The addressed challenges can be categorized as follow:

\subsection{Challenges with Scrum Roles}

Scrum defines specific roles and responsibilities which are somewhat different from what had defined in the traditional software methodologies. Self-organizing teams are the development engine of Scrum. However, reviewing the literature shows that finding and hiring such experts is not easy [10]. Furthermore, sometimes, Scrum Masters force the development teams to be selforganized [10].

Customers active involvement is critical in Scrum framework. Particularly, Product Owner must work with the development team during the project. However, several studies expressed that finding such an active and supportive customer is serious issue [11]. Another issue is associated with Scrum Masters. Most often, software teams hire project managers to play the role of Scrum Master. This is really challenging, because project managers are used to command and control the team; while, Scrum Masters are servant leaders who collaborate with the team members effectively [12].

\subsection{Challenges with Scrum Ceremonies}

Although Scrum defines a few ceremonies, it seems that sometimes Scrum teams face with issues in associated in these ceremonies. Daily stand-up meeting as a short daily meeting, sometimes is not effective as expected because of lack of team member active involvement [13]. Also, in Sprint planning meeting sometimes balancing the workload is a serious challenges [10, 14].

Some other challenges addressed in associated with other ceremonies including Retrospective meetings and Sprint review. People involvement and collaboration in these meetings is not as expected when teams have not defined specific goals before these meetings [13-15].

\subsection{Communication Challenges}

Scrum teams need to be collocated and work closely to avoid formal communication. In this fact, Scrum relies on face-to-face communication. However, the literature shows several challenges regarding providing face-to-face communication primarily because of cultural differences and misunderstandings $[3,16]$. 
International Journal of Software Engineering \& Applications (IJSEA), Vol.8, No.3, May 2017

Lack of trust between the involved people is another critical issue that results is problems and challenges in Scrum adoption $[12,17]$. In fact, in such a people-oriented framework, lack of trust between team members is a serious barrier for effective communication, collaboration, and team performance.

In sum up, reviewing the above challenges, shows that all the challenges are related to the people, their relationships, behaviors, and attitude. Indeed, negative team climate strongly leads to encountering with serious challenges that ultimately would fail the Scrum adoption.

\section{FACILITATORS OF SCRUM AdOPTION}

Reviewing the literature to explore the facilitators and success factors of Scrum adoption reveals that team climate is the primary source of most of them. It means that in case of providing positive team atmosphere, Scrum adoption would be successful. The below are the positive facilitators of Scrum adoption.

\subsection{People Buy-in}

People commitment and buy-in facilitate using and adapting to Scrum effectively [18]. Product Owner need to accept his/her role in managing Product Backlog, Scrum Master must support the team against the encountering obstacles, and Senior managers have to support the teams by providing them with required resources and supporting them in performing their roles [19, 20]. Finally, development team members have to collaborate each other to achieve the highest amount of business value.

\subsection{Team Members' Motivation}

Having motivated team members is a serious facilitator of Scrum adoption. Indeed, such experts adapt themselves to Scrum practices and Agile principles. In some companies, managers define various incentives to motivate the people to actively participate the Scrum and Agile transition process $[18,21]$. Motivated members try to deal with the emerging challenges and find the best strategies to cope with them. Also, having Agile Champions, those who can persuade others to be Agile by their behaviors, promotes and facilitate Scrum adoption as well as other Agile methods $[18,22,23]$.

\subsection{Qualified Experts}

While selecting and hiring qualified experts seem to be hard, it is an important prerequisite of Scrum adoption [18, 24]. Qualified teams have less technical and social challenge while trying Scrum practices and following its principles. These experts also can provide heuristic solutions to solve adoption challenges, such as problems in decision making, cultural challenges and differences and technical challenges [25-27].

\subsection{Continuous Communications and Negotiations}

Due to the people-centric nature of Scrum, it seems that providing facilities to maximizing people interaction and communication results in overcoming the potential human conflicts. In fact, this situation lets the involved people to easily and freely negotiate to make an agreement when they have different ideas $[18,28]$. 
International Journal of Software Engineering \& Applications (IJSEA), Vol.8, No.3, May 2017

In sum up, it seems that providing positive team climate leads to increasing probability of success in applying Scrum in real environments. Where people are working together in a collaborative manner, support each other in performing their responsibilities, steadily negotiate to handle conflicts, and practically respect the Agile principles, Scrum works well.

\section{CONCLUSIONS}

Scrum adoption is a serious project in interested software teams and organizations. Scrum advantages and benefits on the one hand, tempt companies to use it in their projects, and on the other hand, they encounter with various challenges. This study showed that software teams encounter with several challenges in adapting to Scrum which almost all have the root in team climate. Challenges in new roles and responsibilities, following Scrum ceremonies, and providing smooth the people communication and collaborations were the main categories of the challenges that threat the teams. However, positive team climate facilitates Scrum adoption. Providing people buy-in, team members' motivation, hiring qualified experts, and continuous effective communication and negotiations can accelerate the process of Scrum adoption.

\section{REFERENCES}

[1] VersionOne, "VersionOne 11th Annual State of Agile Report," 2017, Available: stateofagile.versionone.com.

[2] K. Beck, A. Cockburn, R. Jeffries, and J. Highsmith. (2001, Feb. 2016). Agile manifesto. Available: http://www.agilemanifesto.org

[3] M. Usman, "Diminution of Issues and Challenges when Using Scrum in Global Software Engineering," International Journal of Technology and Research, vol. 4, no. 2, 2016.

[4] R. K. Gupta and P. Manikreddy, "Challenges in Adapting Scrum in Legacy Global Configurator Project," in 10th International Conference on Global Software Engineering (ICGSE), 2015, pp. 46-50: IEEE.

[5] R. T. Nishijima and J. G. Dos Santos, "The challenge of implementing scrum agile methodology in a traditional development environment," International Journal of Computers \& Technology, vol. 5, no. 2, pp. 98-108, 2013.

[6] K. S. Rubin, Essential Scrum: A Practical Guide to the Most Popular Agile Process. Michigan: Addison-Wesley Professional, 2012.

[7] P. Abrahamsson, J. Ronkainen, and J. Warsta, "Agile software development methods: Review and analysis," VTT Publications, vol. 478, pp. 1-112, 2002.

[8] M. Cohn, Succeeding with Agile: Software Development Using Scrum. Boston, MA: AddisonWesley Professional, 2009.

[9] C. Sims and H. L. Johnson, Scrum: a Breathtakingly Brief and Agile Introduction. San Francisco, CA: Dymaxicon, 2012.

[10] A. Marchenko and P. Abrahamsson, "Scrum in a multiproject environment: An ethnographicallyinspired case study on the adoption challenges," in Agile 2008 Conference, Toronto, ON, 2008, pp. $15-26$.

[11] T. J. Gandomani and M. Z. Nafchi, "Agile transition and adoption human-related challenges and issues: A Grounded Theory approach," Computers in Human Behavior, vol. 62, pp. 257-266, 2016. 
International Journal of Software Engineering \& Applications (IJSEA), Vol.8, No.3, May 2017

[12] T. J. Gandomani, H. Zulzalil, A. A. A. Ghani, A. M. Sultan, and M. Z. Nafchi, "Obstacles to moving to agile software development; at a glance," Journal of Computer Science, vol. 9, no. 5, pp. 620-625, 2013.

[13] J. Srinivasan and K. Lundqvist, "Agile in India: Challenges and lessons learned," in 3rd India Software Engineering Conference, ISEC'10, Mysore, India, 2010, pp. 125-130, New York: ACM.

[14] J. J. Cho, "An exploratory study on issues and challenges of agile software development with scrum," All Graduate Theses and Dissertations, p. 599, 2010.

[15] C. Sigman, "Adapting to scrum: Challenges and strategies," Intercom, vol. 54, no. 7, pp. 16-19, 2007.

[16] L. Cho, "Adopting an agile culture," Chicago, IL, 2009, pp. 400-403.

[17] S. Dorairaj, J. Noble, and P. Malik, "Understanding lack of trust in distributed agile teams: A grounded theory study," in 16th International Conference on Evaluation and Assessment in Software Engineering, EASE 2012, Ciudad Real, Spain, 2012, vol. 2012, pp. 81-90.

[18] T. J. Gandomani, H. Zulzalil, A. A. Abd Ghani, A. B. M. Sultan, and K. Y. Sharif, "Exploring Facilitators of Transition and Adoption to Agile Methods: a Grounded Theory Study," Journal of Software, vol. 7, no. 9, pp. 1666-1678, 2014.

[19] T. Chow and D. B. Cao, "A survey study of critical success factors in agile software projects," Journal of Systems and Software, vol. 81, no. 6, pp. 961-971, 2008.

[20] M. Pikkarainen, O. Salo, R. Kuusela, and P. Abrahamsson, "Strengths and barriers behind the successful agile deployment-insights from the three software intensive companies in Finland," Empirical Software Engineering, vol. 17, no. 6, pp. 675-702, 2012.

[21] K. Conboy, S. Coyle, X. Wang, and M. Pikkarainen, "People over process: Key challenges in agile development," IEEE Software, vol. 28, no. 4, pp. 48-57, 2011.

[22] R. M. Parizi, T. J. Gandomani, and M. Z. Nafchi, "Hidden Facilitators of Agile Transition: Agile Coaches and Agile Champions," in 8th Malaysian Software Engineering Conference (MySEC), Langkawi, Malaysia, 2014, pp. 246-250: IEEE Computer Society.

[23] T. J. Gandomani, H. Zulzalil, A. A. Abdul Ghani, A. B. M. Sultan, and K. Y. Sharif, "How human aspects impress Agile software development transition and adoption," International Journal of Software Engineering and its Applications, vol. 8, no. 1, pp. 129-148, 2014.

[24] A. Pham and P.-V. Pham, Scrum in Action: Agile Software Project Management and Development. USA: Course Technology Ptr, 2011.

[25] N. B. Moe, A. Aurum, and T. Dybå, "Challenges of shared decision-making: A multiple case study of agile software development," Information and Software Technology, vol. 54, no. 8, pp. 853-865, 2012.

[26] J. Ren, Y. Y. Yusuf, and N. D. Burns, "A decision-support framework for agile enterprise partnering," International Journal of Advanced Manufacturing Technology, vol. 41, no. 1-2, pp. 180-192, 2009.

[27] A. L. Asnawi, A. M. Gravell, and G. B. Wills, "Factor analysis: Investigating important aspects for agile adoption in Malaysia," in Asia's Premier Agile and Lean Conference, AgileIndia 2012, Bengaluru, India, 2012, pp. 60-63.

[28] T. Niinimäki, A. Piri, P. Hynninen, and C. Lassenius, "Studying communication in agile software development: A research framework and pilot study," in ICMI-MLMI'09 Workshop on Multimodal Sensor-Based Systems and Mobile Phones for Social Computing, MSSSC'09, Cambridge, MA, 2009. 